\title{
INTERNAL DEGREES OF FREEDOM IN PERTURBED NONLINEAR KLEIN-GORDON EQUATIONS
}

\author{
L. VÁzquez, S. Jiménez, A. Bellorín, L. E. Guerrero \\ AND J. A. GONZÁLEZ
}

\begin{abstract}
We investigate the kink solutions to the generalized nonlinear Klein-Gordon equation in the presence of inhomogeneous forces and nonlocal operators. We have found that the number of kink internal modes can depend on the asymptotic behavior of the kink solution for large values of $|x|$. A list of mechanisms that are capable to create new kink internal modes would contain some of the following items: inhomogeneous perturbations that generate unstable equilibrium positions for the kink, extended de-localized space-dependent perturbations, external perturbations that do not decay exponentially, and nonlocal operators.
\end{abstract}

Mathematics subject classification (2010): 35Q51, 37K40.

Keywords and phrases: solitons, long-range interactions, power-law behaviors.

\section{REFERENCES}

[1] A. A. Abdumalikov, Jr, V. V. Kurin, C. Helm, A. De Col, Y. Koval, and A. V. Ustinov, Nonlocal electrodynamics of long ultranarrow Josephson junctions: experiment and theory, Phys. Rev. B, 74, 134515 (2006), 9 pages.

[2] G. Alfimov, T. Pierantozzi, and L. VÁzquez, Numerical Study of a Nonlocal Sine-Gordon Equation, in Nonlinear Waves, Classical and Quantum Aspects, edited by V. V. Konotov and F. Abdullaev, Kluwer Academic Publishers, Dordrecht, (2004), 121-128.

[3] G. L. Alfimov AND I. D. POPKOv, Magnetic vortices in a distributed Josephson junction with electrodes of finite thickness, Phys. Rev. B, 52 (1995), 4503-4510.

[4] G. L. ALFIMOV AND V. P. SiLIN, On small perturbations of stationary states in a nonlinear nonlocal model of a Josephson junction, Phys. Lett. A, 198 (1995), 105-112.

[5] G. L. Alfimov, V. M. Eleonsky, And L. M. Lerman, Solitary wave solutions of nonlocal sineGordon equations, Chaos, 8 (1998), 257-271.

[6] Y. M. Aliev, V. P. Silin AND S. A. URYUPIN, Theory of nonlinear dispersing waves in Josephson junctions, Superconductivity, 5 (1992), 230-271.

[7] A. R. Bishop, J. A. Krumhansl, And S. E. Trullinger, Solitons in condensed matter: a paradigm, Physica D, 1 (1980), 1-44.

[8] O. Braun AND Y. S. Kivshar, The Frenkel-Kontorova model, Springer-Verlag, Berlin, 2004.

[9] D. K. CAmpbell, J. F. Schonfeld, AND C. A. Wingate, Resonance structure in kink-antikink interactions in $\varphi^{4}$ theory, Physica D, 9 (1983), 1-32.

[10] D. K. Campbell, M. Peyrard, And P. Sodano, Kink-antikink interactions in the double sineGordon equation, Physica D, 19 (1986), 165-205.

[11] D. K. Campbell, S. Flach, And Y. S. Kivshar, Localizing energy through nonlinearity and discreteness, Physics Today, 57 (2004), 43-49.

[12] M. A. Cirone, K. RzążĖsini, W. P. Schleich, F. Straub, and J. A. Wheeler, Quantum anticentrifugal force, Phys. Rev. A, 65, 022101 (2002), 6 pages. 
[13] M. D. Cunha, V. V. Konotop, AND L. VÁzQuez, Small-amplitude solitons in a nonlocal sineGordon model, Phys. Lett. A, 221 (1996), 317-322.

[14] A. S. Dolgov, On localization of oscillations in nonlinear crystal structure, Sov. Phys. Solid State, 28 (1986), 907-909.

[15] S. Flach and C. R. Willis, Discrete breathers, Phys. Rep., 295 (1998), 181-264.

[16] J. A. GonZÁlez And J. A. HoŁyst, Behavior of $\varphi^{4}$ kinks in the presence of external forces, Phys. Rev. B, 45 (1992), 10338-10343.

[17] J. A. GonzÁlez, B. A. Mello, L. I. Reyes, And L. E. Guerrero, Resonance phenomena of a solitonlike extended object in a bistable potential, Phys. Rev. Lett., 80 (1998), 1361-1364.

[18] J. A. GONZÁLEZ, A. BELlorín, AND L. E. GUERRERO, Internal modes of sine-Gordon solitons in the presence of spatiotemporal perturbations, Phys. Rev. E, 65, 065601(R) (2002), 4 pages.

[19] J. A. González, A. Bellorín, And L. E. Guerrero, How to excite the internal modes of sineGordon solitons, Chaos, Solitons \& Fractals, 17 (2003), 907-919.

[20] J. A. GonzÁlez, S. Cuenda, AND A. SÁnCHEZ, Kink dynamics in spatially inhomogeneous media: the role of internal modes, Phys. Rev. E, 75, 036611 (2007), 7 pages.

[21] N. GRøNBECH-JENSEN AND M. R. SAMUELSEN, Long range magnetic interaction between Josephson junctions, Phys. Rev. Lett., 74 (1995), 170-173.

[22] H. FRIEDRICH, Semiclassical and large quantum number limits of the Schröodinger Equation, in Proceedings of the Fourth International Conference on Dynamical Systems and Differential Equations, Wilmington, USA, 2002, 288-294.

[23] L. E. Guerrero, E. LóPEZ-ATENCIO, AND J. A. GonZÁLEZ, Long-range self-affine correlations in a random soliton gas, Phys. Rev. E, 55 (1997), 7691-7695.

[24] A. GuREVICH, Nonlocal Josephson electrodynamics and pinning in superconductors, Phys. Rev. B, 46 (1992), 3187-3190.

[25] J. A. HoŁyst AND H. BENneR, Universal family of kink-bearing models reconstructed from a Pöschl-Teller scattering potential, Phys. Rev. B, 43 (1991), 11190-11196.

[26] Y. M. IVAnchenko And T. K. Soboleva, Nonlocal interaction in Josephson junctions, Phys. Lett. A, 147 (1990), 65-69.

[27] Y. M. IVANChenko And T. K. SoboleVA, Josephson transition with nonlocal interaction, JETP Lett., 51 (1990), 114-117.

[28] M. Kardar, G. PARISI, AND Y.-C. Zhang, Dynamic scaling of growing interfaces, Phys. Rev. Lett., 56 (1986), 889-892.

[29] A. A. Kilbas, T. Pierantozzi, J. J. Trujillo, and L. VÁzquez, On the solution of fractional evolution equations, Journal of Physics A: Mathematical and General, 37 (2004), 3271-3283.

[30] Y. S. KivshaR And B. A. Malomed, Dynamics of solitons in nearly integrable systems, Rev. Mod. Phys., 61 (1989), 763-915.

[31] Y. S. KivshaR, F. Zhang, AND L. VÁZQueZ, Resonant soliton-impurity interactions, Phys. Rev. Lett., 67 (1991), 1177-1180.

[32] Y. S. Kivshar, D. E. Pelinovsky, T. Cretegny, and M. Peyrard, Internal modes of solitary waves, Phys. Rev. Lett., 80 (1998), 5032-5035.

[33] V. G. Kogan, V. V. Dobrovitski, J. R. Clem, Y. Mawatari, and R. G. Mints, Josephson junction in a thin film, Phys. Rev. B, 63, 144501 (2001), 9 pages.

[34] R. S. MACKAY AND S. Aubry, Proof of existence of breathers for time-reversible or Hamiltonian networks of weakly coupled oscillators, Nonlinearitym 7 (1994), 1623-1643.

[35] R. G. Mints AND I. B. SNapiro, Electromagnetic waves in a Josephson junction in a thin film, Phys. Rev. B, 51 (1995), 3054-3057.

[36] P. MIŠKINIS, A nonlocal integrable generalization of the Frenkel-Kontorova model of dislocation, Acta Physica Polonica B, 37 (2006), 2933-2946.

[37] L. Morales-Molina, N. R. Quintero, F. G. Mertens, and A. Sánchez, Internal mode mechanism for collective energy transport in extended systems, Phys. Rev. Lett., 91, 234102 (2003), 4 pages.

[38] M. J. MORITZ, C. ELTSCHKA, AND H. FRIEDRICH, Threshold properties of attractive and repulsive $1 / r^{2}$ potentials, Phys. Rev. A, 63, 042102 (2001), 11 pages.

[39] M. PeyraRd AND D. K. CAMPBell, Kink-antikink interactions in a modified sine-Gordon model, Physica D, 9 (1983), 33-51. 
[40] N. R. Quintero, A. SÁnChez, AND F. G. MERTEns, Existence of internal modes of sine-Gordon kinks, Phys. Rev. E, 62, (2000), R60-R63.

[41] N. R. QUintero, A. SÁnChEZ, AND F. G. MERTEns, Anomalies of ac driven solitary waves with internal modes: Nonparametric resonances induced by parametric forces, Phys. Rev. E, 64, 046601 (2001), 7 pages.

[42] M. R. Remoissenet, Waves called solitons: Concepts and Experiments, Springer-Verlag, Berlin, 1996.

[43] B. Ross, Editor, Fractional Calculus and its Applications, Springer-Verlag, Berlin, 1975.

[44] A. J. Sievers AND S. TAKeno, Intrinsic localized modes in anharmonic crystals, Phys. Rev. Lett., 61 (1988), 970-973.

[45] Y. P. VARSHNI, Semi-classical approximations for the energy lLevels of a two-term inverse power potential, Europhys. Lett., 20 (1992), 295-300.

[46] L. VÁzQuez, W. A. Evans, AND G. RickAYZEN, Numerical investigation of a non-local sineGordon model, Phys. Lett. A, 189 (1994), 454-459.

[47] L. VÁzQUEZ, Fractional diffusion equations with internal degrees of freedom, Journal of Computational Mathematics, 21 (2003), 491-494.

[48] L. VÁzQuez AND R. Vilela-Mendes, Fractionally coupled solutions of the diffusion equation, Applied Mathematics and Computation, 141 (2003), 125-130. 